\title{
Obtenção de mulita porosa a partir da sílica da casca de arroz e do acetato de alumínio
}

\author{
(Porous mullite obtained using silica from \\ rice husk and aluminum acetate)
}

\author{
R. R. Menezes ${ }^{1}$, E. Fagury-Neto ${ }^{2}$, M. C. Fernandes ${ }^{2}$, P. M. Souto ${ }^{2}$, R. H. G. A. Kiminami ${ }^{2}$ \\ ${ }^{1}$ Unidade Acadêmica de Engenharia de Materiais, Universidade Federal de Campina Grande, \\ Av. Aprígio Veloso 882, Campina Grande, PB 58109-970 \\ ${ }^{2}$ Laboratório de Síntese e Processamento de Materiais Cerâmicos, Departamento de Engenharia de Materiais, \\ Universidade Federal de S. Carlos, Rod. Washington Luiz, km 235, S. Carlos, SP 13565-905 \\ romualdomenezes@dema.ufcg.edu.br,ruth@power.ufscar.br
}

\begin{abstract}
Resumo
O grande volume de produção de arroz no mundo gera uma enorme quantidade de rejeito na forma de cascas e de cinzas oriundas da queima da casca. Esses resíduos são fontes de poluição e contaminação, podendo agredir diretamente a saúde da população. Assim, esse trabalho tem por objetivo a obtenção de mulita porosa a partir da sílica da casca de arroz e do acetato de alumínio. O resíduo foi física e quimicamente caracterizado e em seguida misturado com acetato de alumínio para a produção do precursor da mulita. $\mathrm{O}$ material precursor foi caracterizado termicamente e com base nos resultados foi calcinado a $850{ }^{\circ} \mathrm{C}$ e $1200{ }^{\circ} \mathrm{C}$. Os corpos de prova foram queimados a $1500^{\circ} \mathrm{C}$ e $1600{ }^{\circ} \mathrm{C}$ e caracterizados pela determinação de sua porosidade aparente, absorção de água e densidade aparente e por difração de raios X e microscopia eletrônica de varredura. Os resultados indicaram que a sílica é constituída por material amorfo e aglomerados micrométricos de partículas submicrométricas e nanométricas. Com base nos resultados conclui-se que a sílica obtida da casca de arroz e o acetato de alumínio podem ser utilizados com sucesso para a produção de corpos mulíticos porosos com porosidades superiores a $48 \%$.

Palavras-chave: resíduo, reciclagem, casca de arroz, mulita, acetato de alumínio.
\end{abstract}

Abstract

The production of rice around the world generates large amounts of waste in the form of husks and ashes from husks burning, which are sources of environmental contamination and pollution. The aim of this work was obtain porous mullite bodies using the silica from the rice husk and aluminum acetate. The waste material was physically and chemically characterized. The mullite precursor was produced mixing the waste and aluminum acetate. The thermal behavior of mullite precursor was described. The precursor was fired at $850{ }^{\circ} \mathrm{C}$ and $1200{ }^{\circ} \mathrm{C}$ and sample bodies were sintered at 1500 and $1600{ }^{\circ} \mathrm{C}$. Sintered samples were characterized to determine their apparent porosity, water absorption, apparent density, and microstructurally analyzed by X-ray diffraction and scanning electron microscopy. The results indicated that the silica obtained form the rice husk was composed of amorphous material and agglomerates of submicrometer and nanometer particles. The silica and the aluminium acetate can be successfully used as alternative raw materials for the production of mullite ceramics with porosities higher than $48 \%$.

Keywords: wastes, recycling, rice husk, mullite, aluminum acetate.

\section{INTRODUÇÃO}

O Brasil possui uma produção de arroz superior a 11 milhões de toneladas por ano, ocupando o décimo lugar na lista dos produtores mundiais [1]. O grande volume de produção de arroz gera uma enorme quantidade de rejeito na forma de cascas, que são produzidas durante o beneficiamento desse produto. As cascas correspondem a aproximadamente $20 \%$, em peso, das sementes secas [2], o que faz com que a quantidade de resíduo produzido por ano atinja milhões de toneladas. A casca do arroz é de difícil degradação e ocupa um grande volume quando da sua disposição em aterros, o que origina um grave problema ecológico nas grandes regiões produtoras [3]. A maior parte da casca de arroz produzida no Brasil é, em geral, queimada pelos beneficiadores. A energia térmica necessária ao beneficiamento e armazenagem do arroz, o alto custo do transporte devido à baixa densidade de empacotamento das cascas (elevado volume para disposição) e a falta de outros usos significativos para este resíduo fazem da queima a prática mais comum [4], por propiciar uma fonte alternativa de energia e favorecer uma grande redução no volume do resíduo. A casca de arroz e, por conseguinte, o resíduo de sua queima apresenta elevada quantidade de componentes inorgânicos, representando aproximadamente $20 \%$ da casca seca, dos quais, cerca de $95 \%$ são sílica e o restante consiste 
em componentes minoritários, $\mathrm{K}_{2} \mathrm{O}, \mathrm{CaO}, \mathrm{MgO}, \mathrm{MnO}, \mathrm{Al}_{2} \mathrm{O}_{3}$, $\mathrm{P}_{2} \mathrm{O}_{5}$, sendo considerados impurezas em várias aplicações em que se utiliza a casca e o resíduo de sua queima $[2,5]$.

As empresas beneficiadoras de arroz, que utilizam a casca como combustível para a secagem, parbolização do cereal e aquecimento dos silos de armazenamento, são, em geral, empresas de pequeno porte e não possuem processos para o aproveitamento e/ou descarte adequado das cinzas geradas com a queima. Isso faz com que as cinzas sejam depositadas em terrenos baldios ou lançadas em rios e córregos, provocando poluição e contaminação de manaciais e agressão à saúde da população, por contaminar o ar e poder causar silicose. Por outro lado, a reciclagem das cinzas da casca de arroz é uma excelente alternativa para minimizar o impacto ambiental provocado pelo descarte inadequado desse material e a redução dos custos de disposição em aterros controlados. As cinzas vêm se mostrando uma ótima matéria-prima de sílica, gerando um material fino e com alta reatividade. Nesse sentido, a sílica obtida da casca do arroz tem sido empregada com grande sucesso como matéria-prima cerâmica alternativa para a produção de vários materiais [3, 6-12], evidenciando o seu elevado potencial tecnológico. No entanto, a utilização dessa sílica em algumas aplicações cerâmicas requer, por vezes, processos de purificação para a retirada dos componentes minoritários presentes no material que irão contribuir para a formação de fases vítreas no produto cerâmico final. Esses processos envolvem, em geral, tratamentos ácidos antes da queima e/ou tratamentos ácidos pós-queima $[4,5,13,14]$. Com a evolução dos processos de purificação foi possível a utilização da sílica da casca de arroz em várias aplicações cerâmicas, desde as mais tradicionais como tijolos, cimento, agregados em argamassas e concretos e vidros [3], às de alto desempenho como SIALON, carbeto e nitreto de silício, cordierita, mulita, etc.

A utilização da sílica na produção de materiais cerâmicos com elevado desempenho e grande aplicabilidade, como a cordierita e a mulita, incentiva em muito a reciclagem do resíduo da queima da casca, por permitir absorver grandes quantidade desse material e lhe agregar um maior valor. $\mathrm{O}$ que é fundamental para um processo de reciclagem eficiente e auto-sustentável, com enfoque ecológico, mas também econômico.

A mulita é a única fase cristalina estável no sistema $\mathrm{Al}_{2} \mathrm{O}_{3}-\mathrm{SiO}_{2}$, com composição química variável sobre a faixa de $3 \mathrm{Al}_{2} \mathrm{O}_{3} \cdot 2 \mathrm{SiO}_{2}$ a $2 \mathrm{Al}_{2} \mathrm{O}_{3} \cdot \mathrm{SiO}_{2}$. Apresenta ponto de fusão próximo de $1800{ }^{\circ} \mathrm{C}$, baixa densidade, pequeno coeficiente de expansão térmica, elevada resistência mecânica e ao choque térmico e várias outras propriedades que a tornam um dos principais materiais cerâmicos. A sua refratariedade e inércia térmica, associadas à resistência ao choque térmico, permitem seu uso como refratários, acessórios para fornos e como substratos em uma série de aplicações em altas temperaturas $[15,16]$. A mulita é geralmente obtida pela mistura e reação de precursores e/ou matérias-primas de sílica e alumina. Entretanto, mulita homogênea requer altas temperaturas $\left(1700\right.$ a $\left.1800{ }^{\circ} \mathrm{C}\right)$ e prolongadas queimas para sua formação e, mesmo assim, o produto final pode conter alumina alfa e sílica (quartzo ou cristobalita), em virtude da lenta interdifusão dos constituintes dos precursores e/ou matérias-primas ou da mistura inadequada desses materiais [15]. Isto faz necessária a busca e utilização de matérias-primas finas, com elevada reatividade e técnicas de processamento que aumentem a homogeneidade e intimidade de mistura, a fim de se obter corpos mulíticos em menores temperaturas e ciclos de queima.

A utilização de precursores com dimensões submicrométricas e nanométricas favorece tanto o aumento na intimidade da mistura entre os precursores da mulita, como a cinética do processo de síntese por se tratarem de partículas muito reativas. $\mathrm{O}$ acetato de alumínio é um material que ainda não foi estudado como precursor para síntese de mulita, mas apresenta grande potencial por produzir alumina nanométrica após sua decomposição [17]. O acetato de alumínio é um sal solúvel que tem custo relativamente baixo, pode ser encontrado com elevada pureza e finura, o que favorece a homogeneidade do sistema precursor favorecendo a reação de formação da mulita.

A grande disponibilidade de matérias-primas e o largo leque de aplicações fazem a mulita ocupar uma posição de destaque na indústria cerâmica, sendo importante tanto nas cerâmicas convencionais como nas de alto desempenho. Nesse sentido, tem-se observado que o desenvolvimento de cerâmicas porosas de mulita tem recebido considerável atenção nos últimos anos [18-22] em virtude do grande leque de aplicações que podem ser utilizadas [23, 24].

Cerâmicas porosas podem ser utilizadas em sensores de gás, limpadores de água, isoladores térmicos, suportes de catalisadores, trocadores de íons, filtros de gás e metais fundidos e como base em uma série de compósitos [25, 26]. O que evidencia a importância tecnológica dessas cerâmicas e o grande número de setores econômicos que necessitam e utilizam esse tipo de material. Assim, com base na importância tecnológica das cerâmicas porosas, na necessidade de alternativas de reciclagem para a casca de arroz e no grande potencial do acetato de alumínio como fonte de alumina nanométrica e/ou submicrométrica, esse trabalho tem por objetivo a obtenção de mulita porosa a partir da sílica da casca de arroz e do acetato de alumínio.

\section{MATERIAIS E MÉTODOS}

Para a síntese da mulita foram utilizados sílicas obtidas da casca de arroz e acetato de alumínio comercial (Vetec P.A.). A composição química da cinza da casca de arroz foi determinada por fluorescência de raios X no CTCMat, SENAI, SC, após queima a $500{ }^{\circ} \mathrm{C}$ por $4 \mathrm{~h}$.

A casca de arroz foi tratada com ácido nítrico 12 molar a $200{ }^{\circ} \mathrm{C}$ por $6 \mathrm{~h}$; em seguida a casca foi filtrada com água destilada até se obter $\mathrm{pH}$ entre 6 e 7 e seca a $110{ }^{\circ} \mathrm{C}$. Após secagem, a casca foi queimada em uma chapa de aquecimento a aproximadamente $500{ }^{\circ} \mathrm{C}$ por $4 \mathrm{~h}$. O material calcinado foi desaglomerado em moinho de bolas por $1 \mathrm{~h}$ em meio aquoso e esferas de mulita, com Darvan C como defloculante.

O pó obtido foi caracterizado através de difração de 
raios X (Siemens D5100), determinação da densidade por picnometria de He (Micromeritics 1330), determinação da área específica pela técnica de BET (Micromeritics, Gemini 2370), determinação da distribuição do tamanho de partícula (Horiba, Capa 700) e microscopia eletrônica de varredura (Philips XL30 FEG).

Para a síntese da mulita foram utilizadas quantidades de acetato de alumínio e sílica obtida da casca de arroz de modo a atingir a estequiometria da mulita, com $78 \%$ de $\mathrm{Al}_{2} \mathrm{O}_{3} \mathrm{e}$ $22 \%$ de $\mathrm{SiO}_{2}$ no produto final. O material foi disperso em meio aquoso utilizando ultra-som por 30 min e Darvan C como defloculante. A secagem da suspensão foi feita em liofilizador. $\mathrm{O}$ material obtido foi peneirado em peneira com abertura de $45 \mu \mathrm{m}$ (ABNT 325) e caracterizado por calorimetria diferencial de varredura e termogravimetria.

O pó precursor da mulita foi calcinado a $850{ }^{\circ} \mathrm{C}$ e $1200{ }^{\circ} \mathrm{C}$ por $5 \mathrm{~h}$ e $3 \mathrm{~h}$, respectivamente. Em seguida foram confeccionados corpos de prova com $20 \mathrm{~mm}$ de diâmetro por prensagem uniaxial a $30 \mathrm{MPa}$ seguida de prensagem isostática a $100 \mathrm{MPa}$. As pastilhas foram sinterizadas a 1500 e $1600{ }^{\circ} \mathrm{C}$ por $2 \mathrm{~h}$. Após queima, os corpos de prova foram caracterizados por meio da determinação de densidade pelo método de Arquimedes com imersão em água e análise microestrutural por difração de raios X (Siemens D5100) e microscopia eletrônica de varredura (Philips XL30 FEG) das superfícies de fratura.

\section{RESULTADOS E DISCUSSÃO}

A Tabela I apresenta a composição química da cinza da casca de arroz utilizada neste trabalho (sem tratamento ácido) e também uma composição química típica de cinza de casca de arroz [27]. A cinza é composta basicamente por sílica e componentes minoritários, que atingem quantidade superior a 4\%. Dentre os componentes minoritários observa-se elevada quantidade de óxidos fundentes, particularmente $\mathrm{K}_{2} \mathrm{O}$, que tendem a abaixar o ponto de fusão e propiciar a formação de fases vítreas no produto final, o que é extremamente indesejável para a produção de cerâmicas de alto desempenho, que serão utilizadas em altas temperaturas.

$\mathrm{O} \mathrm{K}_{2} \mathrm{O}$ contido na cinza também acelera a cristalização da sílica amorfa em cristobalita [28], o que é indesejável no processo de produção de mulita por poder retardar sua cinética de formação. Por outro lado, comparando-se com os dados publicados [27], nota-se que os teores obtidos encontram-se dentro da faixa observada para esse tipo de material. Os teores de componentes minoritários observados na cinza obtida estão próximos aos limites mínimos apresentados [27] para esse material, à exceção do $\mathrm{K}_{2} \mathrm{O}$, que possui uma quantidade pouco superior à média indicada [27] para esse óxido nas cinzas da casca de arroz.

A Fig. 1 apresenta o padrão de difração de raios $X$ da cinza da casca de arroz após tratamento ácido e queima. A cinza contém sílica na forma amorfa, o que indica que o método de obtenção não favoreceu a cristalização da sílica.

A coloração da sílica obtida é fortemente dependente da presença e teor de componentes minoritários e das condições de queima. Cores acinzentadas e escuras são consequiências de carbono residual da queima e cores púrpuras e amareladas dos outros componentes minoritários (óxidos distintos do $\mathrm{SiO}_{2}$ ). A cinza produzida neste trabalho apresentou uma coloração branca, o que, em conjunto com o resultado obtido com a difração de raios $\mathrm{X}$, indica que o material obtido é altamente reativo e com um teor muito pequeno de óxidos distintos do $\mathrm{SiO}_{2}$.

A densidade obtida para a sílica foi $2,11 \mathrm{~g} / \mathrm{cm}^{3}$. Esse valor é semelhante ao indicado [29] para a densidade da sílica vítrea $\left(2,20 \mathrm{~g} / \mathrm{cm}^{2}\right)$. A densidade da sílica obtida é muito dependente da temperatura de queima e do teor de componentes minoritários (fundentes) presentes no material. Por um lado, o aumento da temperatura leva à redução da quantidade de substâncias voláteis no material e, em conseqüência, ao aumento da porosidade interna da cinza, reduzindo a densidade [3]. Por outro lado, elevadas temperaturas de queima associadas a um alto teor de fundentes no material podem provocar uma pré-sinterização, gerando a formação de agregados, com aumento no tamanho de partículas, redução de porosidade e aumento da densidade. A temperatura utilizada na queima da casca propiciou a obtenção de sílica com baixa densidade e provavelmente alta porosidade.

$\mathrm{O}$ valor da área específica obtido pelo método de BET foi $376,2 \mathrm{~m}^{2} / \mathrm{g}$. Dados [28] oriundos de cinzas queimadas a $400{ }^{\circ} \mathrm{C}$ possuem área superficial em torno de $147 \mathrm{~m}^{2} / \mathrm{g}$ e de $5 \mathrm{~m}^{2} / \mathrm{g}$ após queima a $800{ }^{\circ} \mathrm{C}$. $\mathrm{O}$ valor obtido indica que o tratamento ácido realizado foi extremamente eficiente para a retirada de impurezas, já que o material manteve elevada área específica após o processo de calcinação.

A Fig. 2 apresenta a distribuição de tamanho de partícula da cinza da casca de arroz após o tratamento ácido e queima. O tamanho médio das partículas foi de aproximadamente $8,5 \mu \mathrm{m}$, enquanto $\mathrm{D}_{10}, \mathrm{D}_{50}$ e $\mathrm{D}_{90}$ foram de aproximadamente $0,5 \mu \mathrm{m}, 10 \mu \mathrm{m}$ e $29 \mu \mathrm{m}$, respectivamente.

Tabela I - Composição química da cinza da casca de arroz.

[Table I - Chemical composition of the rice husk ash.]

\begin{tabular}{lcccccccccc}
\hline & $\mathrm{SiO}_{2}$ & $\mathrm{Al}_{2} \mathrm{O}_{3}$ & $\mathrm{Fe}_{2} \mathrm{O}_{3}$ & $\mathrm{CaO}$ & $\mathrm{Na}_{2} \mathrm{O}$ & $\mathrm{K}_{2} \mathrm{O}$ & $\mathrm{MnO}$ & $\mathrm{TiO}_{2}$ & $\mathrm{MgO}$ & $\mathrm{P}_{2} \mathrm{O}_{5}$ \\
\hline Cinza da casca & 95,02 & 0,45 & 0,10 & 0,51 & 0,13 & 1,90 & 0,34 & 0,02 & 0,42 & 0,55 \\
Ref. [27] & $92-96$ & $0,2-3,0$ & $0,1-2,5$ & $0,5-3,0$ & - & $0,3-2,5$ & - & - & - & - \\
\hline
\end{tabular}




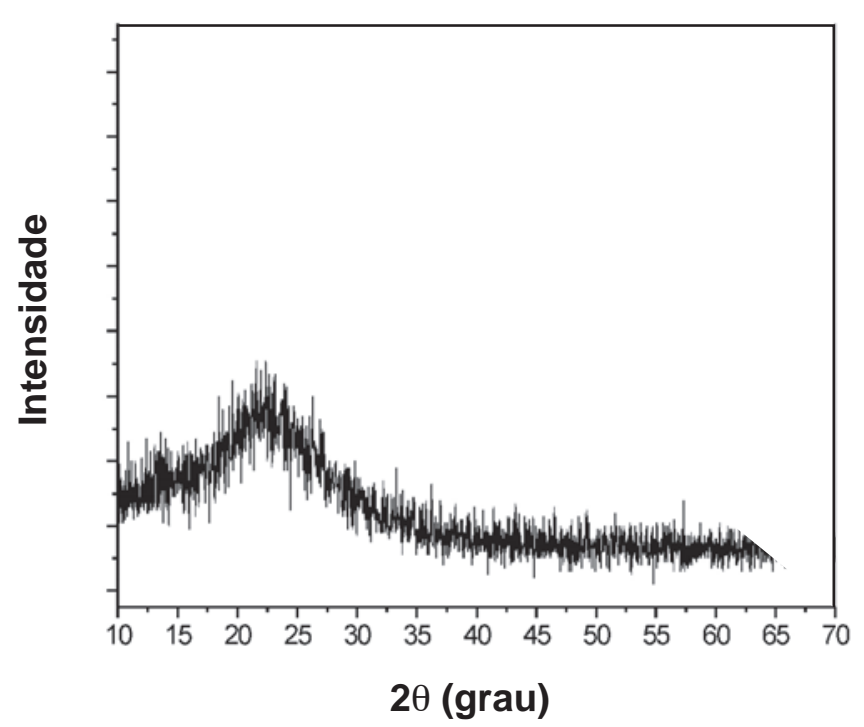

Figura 1: Difratograma de raios $\mathrm{X}$ da cinza da casca de arroz. [Figure 1: X-ray diffraction pattern of the rice husk ash.]

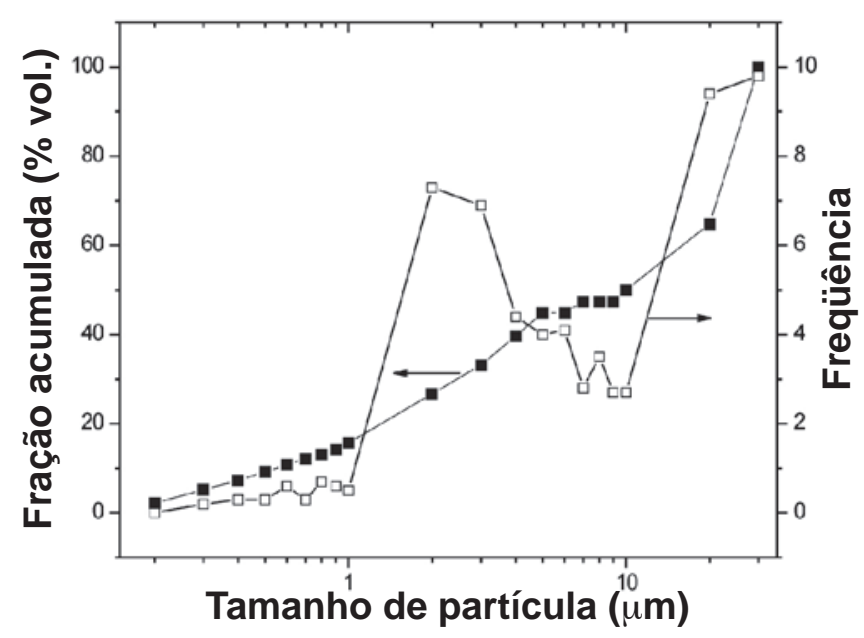

Figura 2: Distribuição de tamanho de partícula da cinza da casca de arroz.

[Figure 2: Particle size distribution of the rice husk ash.]

Há uma concentração de partículas em torno de $2 \mu \mathrm{m}$ e 29 $\mu \mathrm{m}$, tornando a distribuição praticamente bi-modal, o que indica a possível presença de aglomerados de partículas que não foram quebrados durante a desaglomeração.

Considerando a equação AE.D. $\rho=6$ [29], que relacionada o diâmetro $\mathrm{D}$ à área específica $\mathrm{AE}$ de um pó de partículas esféricas de mesmo tamanho e a densidade do material $\rho$ pode-se estimar o valor médio das partículas e avaliar o seu nível de agregação. O tamanho médio das partículas está próximo de $8 \mathrm{~nm}$, que apesar de ser um valor apenas estimativo (em virtude da equação acima possuir várias restrições), é uma indicação que as partículas observadas no ensaio de determinação do tamanho de partículas são agregados porosos de partículas menores.

Componentes minoritários na casca, como os álcalis e partículas com dimensões nanométricas, contribuem para a agregação durante a queima. Por se tratar de partículas com elevada reatividade, a diminuição do teor de álcalis aparenta não ser suficiente para eliminar a agregação, sendo necessária a redução da temperatura de queima. Entretanto, a queima, até o momento, é o melhor processo para separar a sílica dos componentes orgânicos da casca, o que indica que a agregação pode ser reduzida, mas, atualmente, ainda não eliminada.

A Fig. 3 apresenta as micrografias da cinza da casca de arroz. Pode-se observar que as partículas aparentemente da ordem de mícrons são na verdade agregados e aglomerados de partículas menores, da ordem de nanometros ou submícrons, o que vem ao encontro de observações realizadas até o momento pelos dados de área específica e de distribuição granulométrica.

A Fig. 4 mostra as curvas das análises de calorimetria diferencial de varredura e termogravimetria do pó precursor da mulita. Até $500{ }^{\circ} \mathrm{C}$ o material apresenta uma perda de massa decorrente da eliminação de água adsorvida sobre as partículas da cinza, combustão de carbono residual, liberação
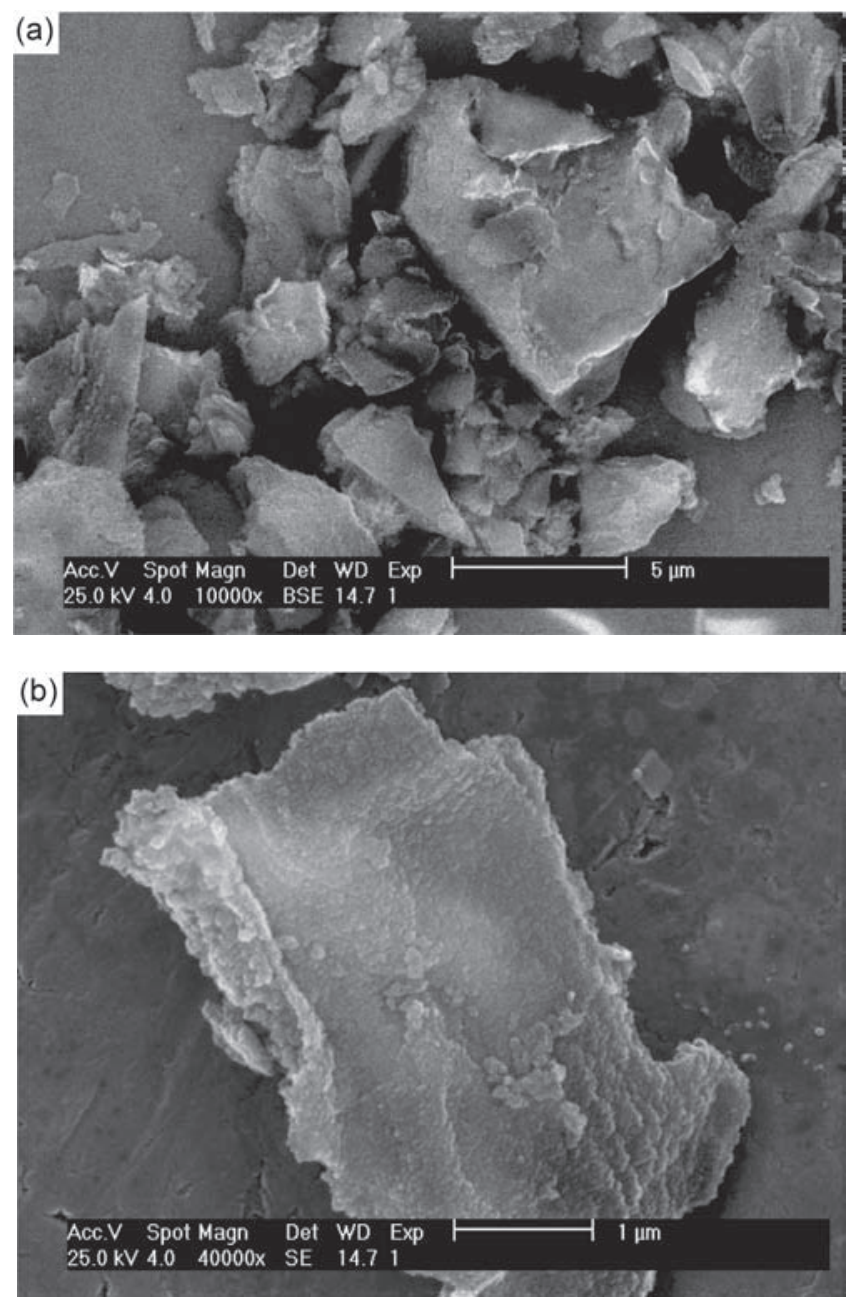

Figura 3: Micrografias obtidas em microscópio eletrônico de varredura da cinza da casca de arroz.

[Figure 3: Scanning electron microscopy micrographs of the rice husk ash.] 


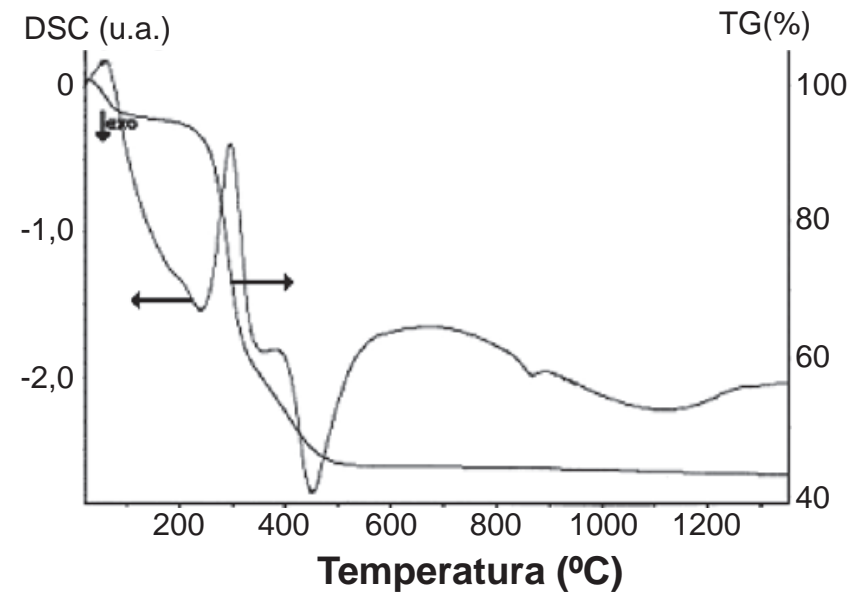

Figura 4: Curvas de calorimetria diferencial de varredura e de termogravimetria da cinza da casca de arroz.

[Figure 4: Differential scanning calorimetry and thermogravimetric curves of the rice husk ash.]

de substâncias voláteis presentes na cinza e eliminação de ácido acético do acetato de alumínio [3, 30], tendo a perda de massa totalizado mais de $50 \%$.

Com base em trabalhos prévios [30], onde se estudou da decomposição do acetato de alumínio liofilizado, verifica-se que os picos endotérmicos a aproximadamente 60 e $300{ }^{\circ} \mathrm{C}$ podem ser, respectivamente, associados a desidroxilação e descarboxilação do acetato de alumínio. O pico exotérmico a aproximadamente $450{ }^{\circ} \mathrm{C}$ pode estar relacionado à formação da primeira alumina que tem característica amorfa. O evento exotérmico em torno de $860{ }^{\circ} \mathrm{C}$ é provavelmente a transformação da alumina amorfa em $\gamma-\mathrm{Al}_{2} \mathrm{O}_{3}$. Em torno de $1150{ }^{\circ} \mathrm{C}$ ocorre a máxima cristalização da sílica [3] e a transformação polimorfica para $\alpha-\mathrm{Al}_{2} \mathrm{O}_{3}$, evidenciadas por difração de raios X, Fig. 5.

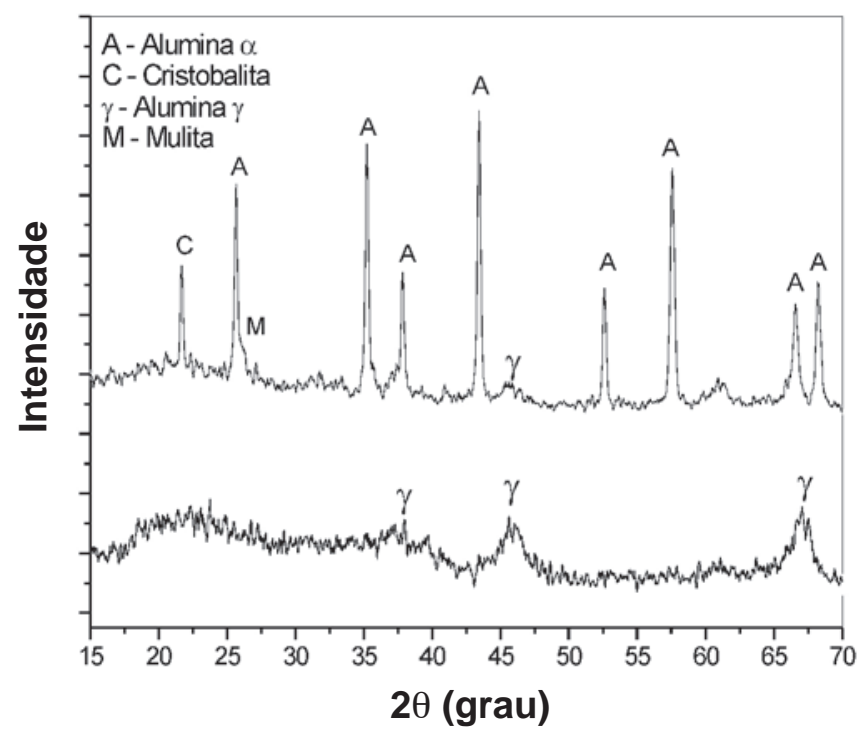

Figura 5: Difratogramas de raios $\mathrm{X}$ do precursor da mulita após queima.

[Figure 5: X-ray diffraction patterns of the fired mullite precursor.]
Pode-se observar a presença da alumina $\gamma$ e a existência de pequena quantidade de mulita após queima a $1150{ }^{\circ} \mathrm{C}$. Trabalhos anteriores [30] observaram que a eliminação das fases intermediárias da alumina e a presença de apenas alumina $\alpha$ quando se utiliza o acetato liofilizado como precursor de alumina são obtidas apenas após calcinação a $1200{ }^{\circ} \mathrm{C}$. Assim, o precursor foi calcinado a $850^{\circ} \mathrm{C}$ e $1200^{\circ} \mathrm{C}$ afim de avaliar o efeito da presença das fases intermediária da alumina na porosidade do produto final.

Os corpos conformados a partir dos pós calcinados a 850 e $1200{ }^{\circ} \mathrm{C}$ foram sinterizados, como mencionado anteriormente, a $1500 \mathrm{e} 1600^{\circ} \mathrm{C}$. A Fig. 6 apresenta os padrões de difração de raios $\mathrm{X}$ das amostras após sinterização. As amostras sinterizadas a $1600^{\circ} \mathrm{C}$ apresentaram apenas mulita como fase cristalina na sua microestrutura final, enquanto que as amostras sinterizadas a $1500^{\circ} \mathrm{C}$ apresentaram mulita e alumina como fases cristalinas.

A Tabela II apresenta as características das amostras sinterizadas. Verifica-se que as amostras calcinadas a $850^{\circ} \mathrm{C}$ apresentaram uma porosidade aparente significativamente maior que as calcinadas a $1200{ }^{\circ} \mathrm{C}$, o que pode estar associado à natureza física do precursor utilizado. $\mathrm{O}$

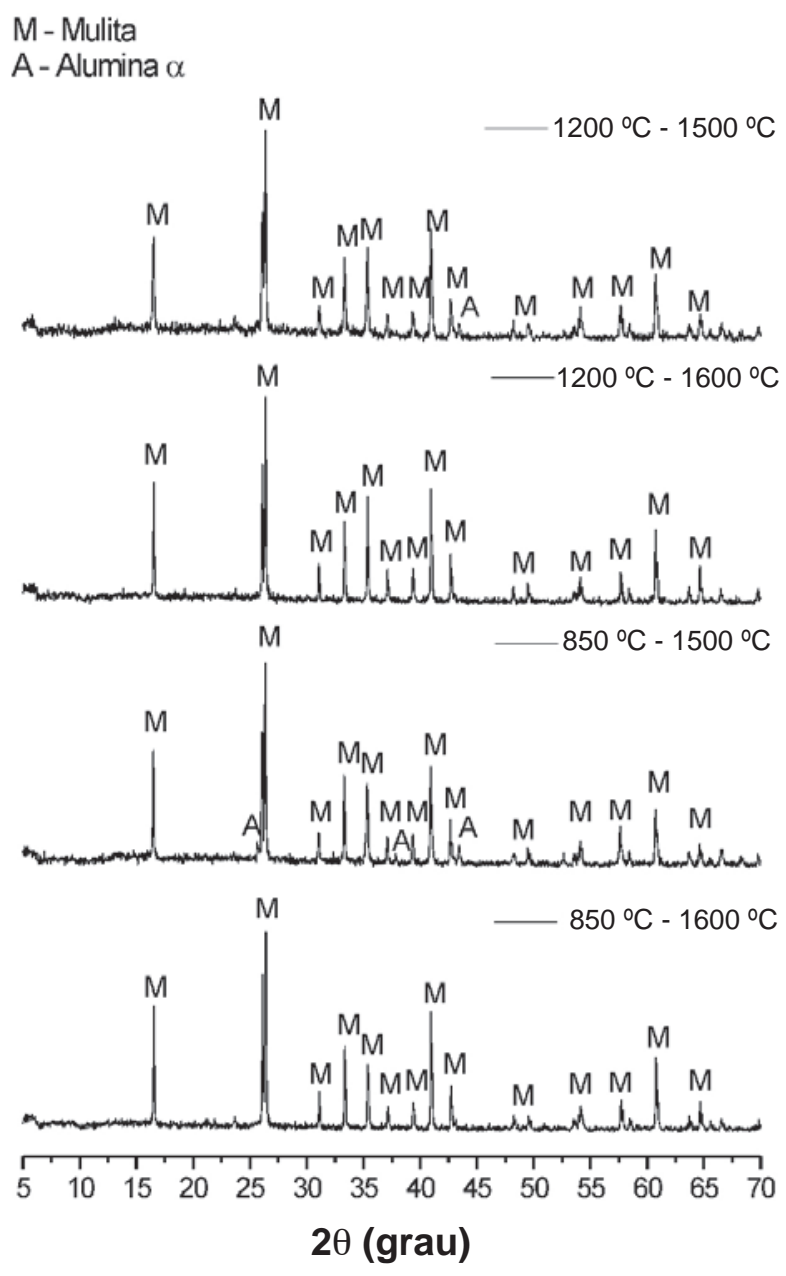

Figura 6: Difratogramas de raios $X$ do material sinterizado. [Figure 6: X-ray diffraction patterns of the sintered material.] 
precursor era constituído por uma sílica muito fina (e reativa) e por uma alumina também muito fina (nanométrica) [30], o que possivelmente fez com que o processo de calcinação em maior temperatura propiciasse uma agregação e uma diminuição da porosidade do pó, partindo-se então, de corpos de prova a verde mais densos (densidade a verde de $38 \%$ nas amostras calcinadas a $850{ }^{\circ} \mathrm{C}$ contra uma densidade de $49 \%$ nas de $1200^{\circ} \mathrm{C}$ ). Outro fator que possivelmente influenciou muito a maior porosidade dos sistemas calcinados a $850{ }^{\circ} \mathrm{C}$ é o fato da alumina apresentar uma severa retração quando da passagem de sua forma gama para alfa. Isso dificulta muito o processo de densificação quando se trabalha com a sinterização de aluminas partindo-se de polimorfos de transição e, no presente estudo, favoreceu a obtenção de maior porosidade nos produtos finais, tal como esperado.

$\mathrm{O}$ procedimento utilizado possibilita produzir corpos com porosidade aparente superior a $48 \%$ após sinterização a $1500{ }^{\circ} \mathrm{C}$. A sinterização a $1600{ }^{\circ} \mathrm{C}$ reduziu a porosidade dos corpos produzidos, independentemente da temperatura de calcinação; entretanto, essa redução foi mais acentuada quando o precursor foi calcinado a $1200{ }^{\circ} \mathrm{C}$.

ATabela II apresenta de forma aproximada a porosidade real dos corpos produzidos, tomando como referência a densidade teórica da mulita, $3,16 \mathrm{~g} / \mathrm{cm}^{3}$. Com base nessa aproximação da porosidade real (uma estimativa, já que os corpos podem conter fases vítreas e os sinterizados a $1500^{\circ} \mathrm{C}$ contém alumina residual, o que faz que a densidade do material final não seja $3,16 \mathrm{~g} / \mathrm{cm}^{3}$, em virtude da fase vítrea presente diminuir um pouco a densidade real e a alumina residual aumentála) pode-se observar que, de forma geral, a porosidade presente nos materiais que foram calcinados a $850{ }^{\circ} \mathrm{C}$ foi predominantemente aberta. No entanto, a porosidade dos calcinados a $1200{ }^{\circ} \mathrm{C}$ foi em grande parte fechada, particularmente nos corpos sinterizados a $1600{ }^{\circ} \mathrm{C}$, onde se observou que a estimativa da porosidade real fornece valores da ordem de $25 \%$, enquanto que a porosidade aparente (aberta) foi de apenas 3,7\%.

Tabela II - Características físicas dos corpos de prova sinterizados.

[Table II - Physical characteristics of the sintered samples.]

\begin{tabular}{|c|c|c|c|c|}
\hline Amostras & $\begin{array}{l}\mathrm{ABS}^{\mathrm{c}} \\
(\%)\end{array}$ & $\begin{array}{l}\text { Porosidade } \\
\text { aparente }^{\mathrm{d}} \\
(\%)\end{array}$ & $\begin{array}{c}\text { Densidade } \\
\text { aparente }^{\mathrm{e}} \\
\left(\mathrm{g} / \mathrm{cm}^{3}\right)\end{array}$ & $\begin{array}{c}\text { Porosidade } \\
\text { realf }^{\mathrm{f}} \\
(\%)\end{array}$ \\
\hline $\begin{array}{l}C^{\text {a }} 850^{\circ} \mathrm{C} \\
S^{b} 1500^{\circ} \mathrm{C}\end{array}$ & 32,07 & 48,30 & 1,51 & 52,35 \\
\hline $\begin{array}{l}C^{a} 850^{\circ} \mathrm{C}, \\
S^{b} 1600{ }^{\circ} \mathrm{C}\end{array}$ & 19,72 & 36,31 & 1,84 & 41,75 \\
\hline $\begin{array}{l}C^{a} 1200^{\circ} \mathrm{C}, \\
S^{b} 1500^{\circ} \mathrm{C}\end{array}$ & 10,67 & 21,56 & 2,02 & 36,03 \\
\hline $\begin{array}{l}C^{\mathrm{a}} 1200^{\circ} \mathrm{C}, \\
\mathrm{S}^{\mathrm{b}} 1600^{\circ} \mathrm{C}\end{array}$ & 1,54 & 3,67 & 2,38 & 24,79 \\
\hline
\end{tabular}

Estudos [31] vêm buscando a produção de corpos mulíticos porosos utilizando resíduos como matérias-primas alternativas, entretanto eles não atingiram porosidades tão elevadas como a atingida nesse trabalho (superior a $48 \%$ ). Nesses estudos não foram obtidos corpos puramente mulíticos, sendo observada a presença de grande quantidade de alumina residual em virtude da baixa reatividade do resíduo utilizado. O que ressalta a versatilidade e potencialidade do resíduo da casca de arroz como fonte alternativa de sílica para a indústria cerâmica e os bons resultados obtidos no presente trabalho.

As Figs. 7 e 8 apresentam as micrografias das amostras sinterizadas. Na Fig. 7 pode-se observar que as amostras calcinadas a $850{ }^{\circ} \mathrm{C}$ e sinterizadas a $1500{ }^{\circ} \mathrm{C}$ apresentaram uma microestrutura com caráter "esponjoso", com a maioria dos poros possuindo pequenas dimensões (da ordem de mícrons ou menores) e poucos poros com grandes dimensões, da ordem de $10 \mu \mathrm{m}$. As amostras calcinadas a $850{ }^{\circ} \mathrm{C}$ e sinterizados a $1600{ }^{\circ} \mathrm{C}$, apesar da elevada porosidade (constituída em maior parte por poros interconectados), apresentaram uma microestrutura com características de maior densificação comparativamente as amostras sinterizadas a $1500{ }^{\circ} \mathrm{C}$ e, aparentemente, um
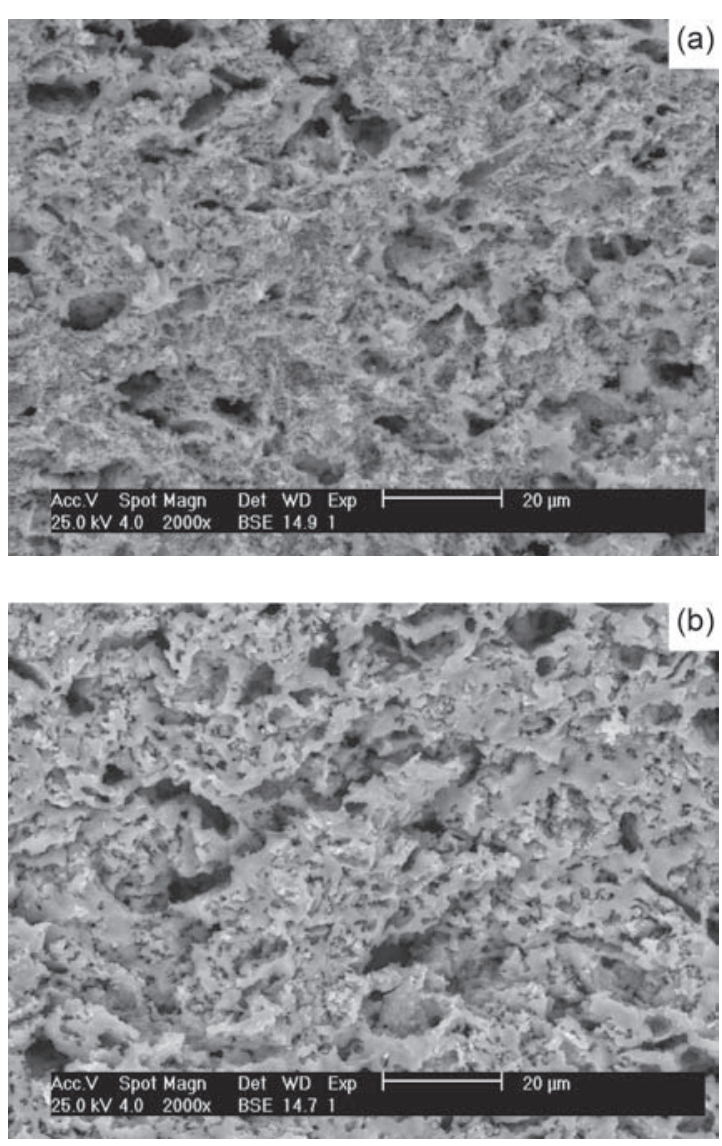

Figura 7: Micrografias obtidas em microscópio eletrônico de varredura do material calcinado a $850{ }^{\circ} \mathrm{C}$ e sinterizado a) $1500{ }^{\circ} \mathrm{C}$ e b) $1600{ }^{\circ} \mathrm{C}$.

[Figure 7: SEM micrographs of the material fired at $850^{\circ} \mathrm{C}$ and sintered at a) $1500^{\circ} \mathrm{C} \mathrm{e} \mathrm{b)} 1600^{\circ} \mathrm{C}$.] 
aumento no tamanho dos poros, observando-se poros da ordem de $15 \mu \mathrm{m}$.

Na Fig. 8 observa-se que as amostras calcinada a $1200^{\circ} \mathrm{Ce}$ sinterizadas a $1500{ }^{\circ} \mathrm{C}$ apresentaram uma densificação maior que as calcinadas a $850^{\circ} \mathrm{C}$, mas ainda uma microestrutura contendo grande quantidade de poros interconectados. No entanto, verifica-se que há grande quantidade de poros grandes (superiores a $10 \mu \mathrm{m}$ ), chegando a atingir tamanhos próximos de $20 \mu \mathrm{m}$. Os materiais calcinados a $1200{ }^{\circ} \mathrm{C}$ e sinterizados a $1600{ }^{\circ} \mathrm{C}$ apresentaram uma microestrutura significativamente distinta das observadas nas outras amostras. Há uma grande quantidade de poros que são predominantemente fechados e de grandes dimensões, atingindo, grande parte deles, tamanhos próximos de $20 \mu \mathrm{m}$. As micrografias vêm ao encontro dos resultados apresentados na Tabela II, evidenciando que a forma e a quantidade da porosidade variam de acordo com a temperatura de calcinação do precursor. As micrografias também evidenciam que a utilização de temperaturas de sinterização próximas de $1600{ }^{\circ} \mathrm{C}$ reduzem significativamente a porosidade do material, tal como observado em outros estudos [21, 22, 26]. Isso indica que menores temperaturas de sinterização, como por exemplo
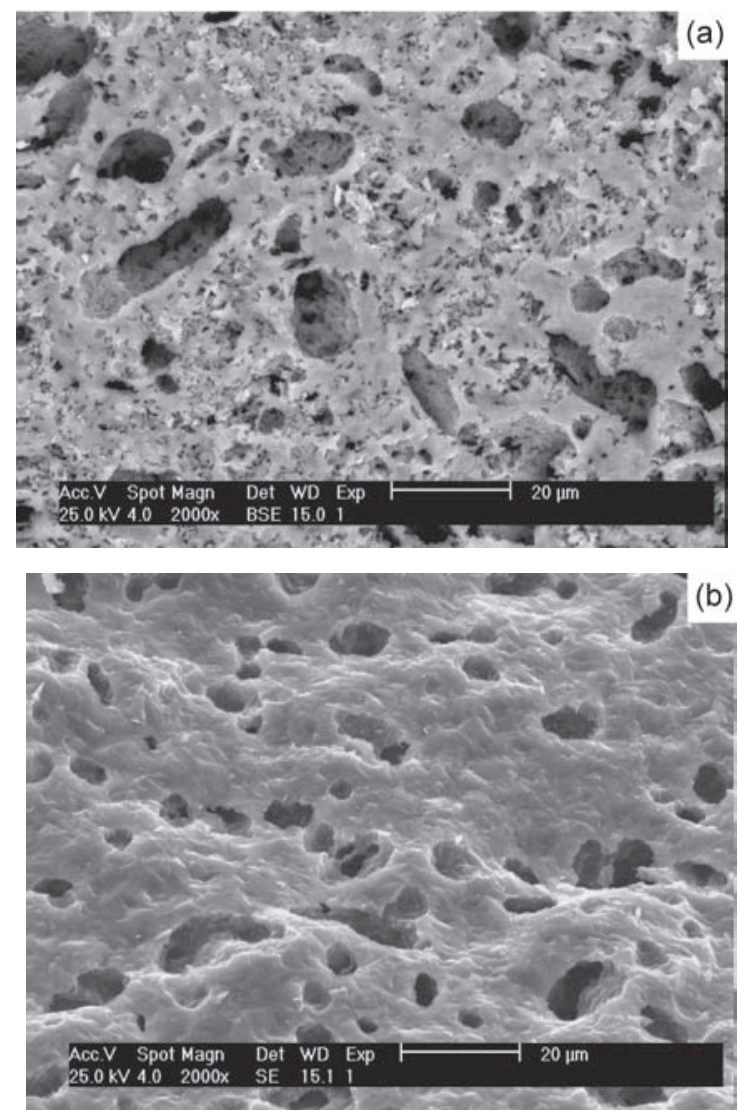

Figura 8: Micrografias obtidas em microscópio eletrônico de varredura do material calcinado a $1200{ }^{\circ} \mathrm{C}$ e sinterizado a) $1500{ }^{\circ} \mathrm{C}$ e b) $1600{ }^{\circ} \mathrm{C}$.

[Figure 8: SEM micrographs of the material fired at $1200{ }^{\circ} \mathrm{C}$ and sintered at a) $1500^{\circ} \mathrm{C} \mathrm{e} \mathrm{b)} 1600^{\circ} \mathrm{C}$.]
$1500{ }^{\circ} \mathrm{C}$, são mais adequadas para a produção de corpos mulíticos porosos. No entanto, menores temperaturas de sinterização nem sempre produzem corpos mulíticos ou altamente mulíticos (corpos com apenas pequenas quantidades de alumina residual), o que faz com que seja necessária a utilização de precursores altamente reativos, tal como a sílica obtida da casca do arroz e a alumina de transição obtida a partir do acetato de alumínio (alumina nanométrica [30]). Nesse sentido, os resultados obtidos destacam a grande potencialidade da sílica obtida a partir da casca de arroz e do acetato de alumínio em aplicações cerâmicas que requerem elevada reatividade das matériasprimas e menores temperaturas de sinterização, como é o caso dos materiais porosos.

Atualmente várias pesquisas vêm buscando alternativas para o aumento da reciclagem de resíduos industriais, por meio da produção de materiais cerâmicos com maior valor agregado a fim de estimular a reciclagem e a redução do descarte de resíduos e desperdício dos recursos naturais. Entretanto, em vários estudos o resíduo estudado atua como uma matéria-prima de qualidade inferior as convencionais, degradando as características do produto final. No entanto, os resultados desse trabalho demonstram que a sílica obtida da casca de arroz pode ser utilizada como uma matéria-prima alternativa com excelente desempenho para a produção de materiais mulíticos porosos.

\section{CONCLUSÕES}

O processo utilizado para a produção da sílica possibilitou obter um material amorfo constituído de pequenos aglomerados porosos de partículas nanométricas e sub-micrométricas com elevada área superficial. A porosidade do produto final é dependente da temperatura utilizada para a calcinação dos precursores e que a adequada combinação das temperaturas de calcinação e sinterização possibilita obter corpos mulíticos com porosidade aberta de aproximadamente $50 \%$. A sílica obtida da casca de arroz e o acetato de alumínio são excelentes matérias-primas precursoras para a produção de mulita.

\section{AGRADECIMENTOS}

À FAPESQ/MCT/CNPq (Proc. 001/06) pelo apoio financeiro.

\section{REFERÊNCIAS}

[1] IBGE, Levantamento Sistemático da Produção Agrícola, Confronto das Safras de 2006 e 2007, http://www.ibge.gov. br, acessado em abril de 2007.

[2] D.F. Houston, Rice Hull, Rice Chemistry and Technology,

Am. Assoc. Cereal Chemi. Inc., New York (1972) 301.

[3] V. P. Della, I. Künh, D. Hotza, Química Nova 24, 6 (2001) 778. 
[4] M. F. de Souza, P. S. Batista, I. Regiani, J. B. L. Liborio, D. P. F. Souza, Mater. Res. 3, 2 (2000) 25.

[5] M. F. de Souza, W. L. E. Magalhães, M. C. Persegil, Mater. Res. 5, 4 (2002) 467.

[6] J. B. Lee, I. B. Cutler, Am. Ceram. Soc. Bull. 54, 2 (1975) 195.

[7] S. B. Hanna, L. M.Farag, N.A.L. Mansour, Thermochim. Acta 81 (1984) 77.

[8] I. A. Rahman, F. L. Riley, J. Eur. Ceram. Soc. 5 (1989) 11.

[9] N. L. Kumar, D. Das, Res. Ind. 37 (1992) 141.

[10] R. V. Krishnarao, J. Eur. Ceram. Soc. 12 (1993) 395.

[11] I. A. Rahman, M. I. Saleh, Mater. Lett. 23 (1995) 157.

[12] M. F. Souza, J. Yamamoto, Cerâmica 45, 291 (1999) 1.

[13] J. James, M. Subba Rao, Thermochim. Acta 97 (1986) 329.

[14] C. Real, M. D. Alcalá, J. M Criado, J. Am. Ceram. Soc. 79, 8 (1996) 2012.

[15] G. Y. Meng, R. A. Huggins, Mater. Res. Bull. 18, 5 (1983) 581.

[16] T. Mah, K. S. Mazdiyasni, J. Am. Ceram. Soc. 66, 10 (1983) 699.

[17] E. Fagury-Neto, R. H. G. A. Kiminami, Anais do 47. Cong. Bras. Cerâm., J. Pessoa, PB (2003) cdrom.

[18] X. Miao, Mater. Lett. 38 (1999) 167.

[19] R. Atisivan, S. Bose, A. Bandyopadhyay, J. Am. Ceram.
Soc. 84 (2001) 221.

[20] Y. F. Liu, X. Q. Liu, H. Wei, G. Y. Meng, Ceram. Int. 27 (2001) 1.

[21] R. Barea, M. I. Osendi, P. Miranzo, J. M. F. Ferreira, J. Am. Ceram. Soc. 88, 3 (2005) 777.

[22] R. Barea, M. I. Osendi, J. M. F. Ferreira, P. Miranzo, Acta Mater. 53 (2005) 3313.

[23] J. Saggie-Woyansky, C. Scott, W. P. Minear, Am. Ceram. Soc. Bull. 71, 11 (1982) 1674.

[24] H. Fujita, G. Jefferson, R. M. McMeeking, F. W. Zok, J. Am. Ceram. Soc. 87, 2 (2004) 261.

[25] R. E. Loehman, K. Ewsuk, A. P. Tomsia, J. Am. Ceram. Soc. 76, 1 (1996) 27.

[26] J. H. She, T. Ohji, Mater. Chem. Phys. 80 (2003) 610.

[27] F. Singer, S. S. Singer, Industrial Ceramic, Chapman \& Hall, Londres (1971) 1223.

[28] Y. Nakata, M. Suzuki, T. Okutani, J. Jpn. Ceram. Soc. 97 (1989) 830.

[29] J. S. Reed, Principles of Ceramics Processing, $2^{\mathrm{a}}$ Ed., John Wiley, New York (1938) 640.

[30] E. Fagury-Neto, Tese de Doutorado, UFSCar, S. Carlos (2005).

[31] R. R. Menezes, M. I. Santana, L. N. L. Santana, G. A. Neves, H. L. Lira, H. C. Ferreira, Waste Management and Research, no prelo.

(Rec. 18/06/2007, Rev. 15/10/2007, Ac. 14/12/2007) 